\title{
Neuromodulation techniques for acute and preventive migraine treatment: a systematic review and meta-analysis of randomized controlled trials
}

Xavier Moisset $^{1^{*}}$ (D), Bruno Pereira ${ }^{1}$, Daniel Ciampi de Andrade ${ }^{2}$, Denys Fontaine ${ }^{3}$, Michel Lantéri-Minet ${ }^{4}$ and Jérôme Mawet ${ }^{5}$

\begin{abstract}
Background: Several neuromodulation methods exists for migraine treatment. The aim of the present study was to perform a systematic review and meta-analysis of randomized controlled trials (RCTs) focusing on migraine treatment using neurostimulation methods.

Methods: We searched Medline and Embase up to July 1, 2020 for RCTs reporting acute or preventive treatment of migraine with either non-invasive or invasive neurostimulation methods. Two researchers independently assessed the eligibility of the retrieved studies and extracted data. Outcomes for the quantitative synthesis were $2 \mathrm{~h}$ pain free for acute treatment and headache days per month for preventive treatment. We performed subgroup analyses by treatment (stimulation method and site of application). Estimates were pooled using random-effects metaanalysis.

Results: Thirty-eight articles were included in the qualitative analysis (7 acute, 31 preventive) and 34 in the quantitative evaluation ( 6 acute, 28 preventive). Remote electrical neuromodulation (REN) was effective for acute treatment. Data were insufficient to draw conclusions for any other techniques (single studies). Invasive occipital nerve stimulation (ONS) was effective for migraine prevention, with a large effect size but considerable heterogeneity, whereas supra-orbital transcutaneous electrical nerve stimulation (TENS), percutaneous electrical nerve stimulation (PENS), and high-frequency repetitive transcranial magnetic stimulation (rTMS) over the primary motor cortex (M1) were effective, with small to medium effect sizes. Vagus-nerve stimulation, left prefrontal cortex rTMS, and cathodal transcranial direct current stimulation (tDCS) over the M1 had no significant effect and heterogeneity was high.

(Continued on next page)
\end{abstract}

\footnotetext{
* Correspondence: xavier.moisset@gmail.com

${ }^{1}$ Service de Neurologie, Biostatistics unit (DRCI), Université Clermont

Auvergne, CHU de Clermont-Ferrand, Inserm, Neuro-Dol, 58 rue Montalembert, F-63000 Clermont-Ferrand, France

Full list of author information is available at the end of the article
}

(C) The Author(s). 2020 Open Access This article is licensed under a Creative Commons Attribution 4.0 International License, which permits use, sharing, adaptation, distribution and reproduction in any medium or format, as long as you give appropriate credit to the original author(s) and the source, provide a link to the Creative Commons licence, and indicate if changes were made. The images or other third party material in this article are included in the article's Creative Commons licence, unless indicated otherwise in a credit line to the material. If material is not included in the article's Creative Commons licence and your intended use is not permitted by statutory regulation or exceeds the permitted use, you will need to obtain permission directly from the copyright holder. To view a copy of this licence, visit http://creativecommons.org/licenses/by/4.0/. The Creative Commons Public Domain Dedication waiver (http://creativecommons.org/publicdomain/zero/1.0/) applies to the data made available in this article, unless otherwise stated in a credit line to the data. 
(Continued from previous page)

Conclusion: Several neuromodulation methods are of potential interest for migraine management, but the quality of the evidence is very poor. Future large and well-conducted studies are needed and could improve on the present results.

Keywords: Neurostimulation, Remote electrical neuromodulation, Occipital nerve stimulation, Transcutaneous electrical nerve stimulation, Percutaneous electrical nerve stimulation (PENS), Repetitive transcranial magnetic stimulation, Vagus-nerve stimulation, Transcranial direct current stimulation

\section{Key findings}

Remote electrical neuromodulation (REN) seems effective for acute treatment.

Invasive occipital nerve stimulation (ONS) is effective for chronic migraine prevention.

Supra-orbital transcutaneous electrical nerve stimulation (TENS), percutaneous electrical nerve stimulation (PENS), and high-frequency repetitive transcranial magnetic stimulation (rTMS) over the motor cortex (M1) are effective for migraine prevention.

\section{Introduction}

According to the Global Burden of Disease study, more than 1 billion people were suffering from migraine in 2016, making migraine one of the most prevalent neurological disorders worldwide [1]. Migraine is even the first cause of disability worldwide among women between the age of 15 and 49 years. Although many pharmacological treatments can be proposed, their efficacy and safety are only partial [2]. Despite the arrival of new drugs, such as those targeting CGRP, certain patients still do not experience optimal relief and other treatments are needed. Moreover, certain patients are reluctant to use pharmacological treatments.

Neuromodulation can be defined as an intervention (drug or procedure) that potentiates or inhibits the transmission of a nerve impulse but is not the actual means of transmission itself [3]. Many medical and interventional techniques can be categorized as neuromodulatory according to this nomenclature and the classification of the various neuromodulatory approaches frequently varies. One frequently used approach is to identify the nervous structure that is targeted (e.g., peripheral nerves, spinal cord, cortex) and then classify the techniques into invasive and noninvasive.

Several non-invasive and even invasive neurostimulation methods have been proposed for acute or preventive migraine treatment. This technology is emerging as a practical and safe alternative to conventional pharmacological treatment of migraine, especially for sensitive patient populations (e.g., pregnant women or adolescents) or those affected by poor tolerability or lack of efficacy of pharmacological approaches. Additionally, nonpharmacological neuromodulatory approaches may even be cost-effective in certain instances [4]. To date, no systematic review combined with meta-analysis of randomized controlled trials (RCTs) on all neurostimulation methods has been published. Thus, we aimed to provide an original comprehensive systematic review and metaanalysis of RCTs focusing on neurostimulation techniques for migraine treatment.

\section{Methods}

The study was submitted to PROSPERO on April 23rd, 2020 (CRD42020181494).

\section{Procedures}

The systematic literature review was performed according to the Preferred Reporting Items for Systematic Reviews and Meta-Analyses (PRISMA) statements [5] and we used a standardized review and data extraction template (Additional file 1). RCTs published as full reports in peer-reviewed journals from inception to May 20, 2020 were identified using PubMed/MEDLINE and Embase. The same databases were further updated up to July 1, 2020.

The target population was patients of any age, including children, with migraine according to the international classification of headache disorders (ICHD) criteria [6]. The migraine conditions considered included both episodic and chronic migraine, either with or without aura. Studies focusing on other headache types, especially tension-type headaches or cluster headaches, were excluded.

The inclusion criteria were in accordance with current methodological guidelines and previous systematic reviews [7-11]: randomized design; comparison with a control group (placebo or comparator) over a follow-up period of at least 4 weeks for preventive treatments (i.e. at least 4 weeks of assessment of the efficacy of active treatment and of comparator in the case of crossover trials) and at least $2 \mathrm{~h}$ for acute treatment; at least $10 \mathrm{pa}-$ tients per group; pain assessed as a primary or secondary outcome (number of headache days/month for preventive treatment; proportion of pain-free patients $2 \mathrm{~h}$ after treatment for acute treatment); and studies published as full reports. As achieving blinding can be difficult or 
even impossible for several neurostimulation techniques, such a design was not required.

\section{Evidence summary and reporting}

We used the Grading of Recommendations Assessment, Development and Evaluation (GRADE) system to assess the risk of bias for individual studies and groups of studies.

\section{Risk of bias in individual trials}

Two review authors (XM and JM) independently assessed the risk of bias for each study using the GRADE system for individual studies. As proposed in previous systematic reviews $[10,11]$, we assessed the following for each study: (1) random sequence generation (checking for possible selection bias) and allocation concealment, (2) blinding of participants (checking for possible performance bias), (3) blinding of evaluators, (4) incomplete outcome data (checking for possible attrition bias due to the amount, nature, or handling of incomplete outcome data), (5) statistical methods, (6) sample size calculation, (7) selective reporting, (8) carryover effect, evaluated for crossover studies and noted as "not applicable" for parallel group studies, and (9) the presence of any other bias evaluated separately, including, in particular, small sample size.

The overall quality of the study was considered "very high" if no bias was noted, "high" if there were only one or two biases, "moderate" if there were three or four, and "low to very low" if there were five or more, as proposed elsewhere [11].

\section{Outcome measures}

We conducted a meta-analysis for this systematic study. An overall meta-analysis was not appropriate as the various techniques have very different mechanisms of action and dosing. Thus, metanalyses were performed grouping stimulation techniques by type.

We report the difference in headache days/month for preventive treatments and/or the responder rate for a $50 \%$ decrease in headache days (or alternatively, a 30\% decrease). The number of headache days per month was chosen instead of the number of migraine days per month as this measure was more consistently available. For acute treatment, we report the proportion of pain-free patients at $2 \mathrm{~h}$, as recommended [9], and/or, alternatively, the absolute difference in pain reduction at $2 \mathrm{~h}$ and/or pain relief at $2 \mathrm{~h}$. Efficacy was assessed on the basis of effect size or absolute difference between active and placebo or sham, or number needed to treat (NNT) (Additional file 2 for acute treatment and 3 for preventive treatment). Effects on other outcome measures, such as quality of life, need for rescue medication, and Patient Global Impression of Change score, were reported when relevant (for example, if no efficacy was observed for the primary outcome measure), but were reported as secondary outcomes. Serious and common $(>10 \%$ incidence) reported adverse events and dropout due to adverse effects were recorded (Additional files 2 and 3).

Statistical analysis was performed using Stata software (version 15, StataCorp, College Station, US). The metaanalysis accounted for between- and within-study variability. The non-independence of data due to study effect was addressed using random-effects models [12] to estimate relative risks (RR) and standardized paired mean differences (SMD) and their 95\% confidence intervals rather than the usual statistical tests. Means and standard-deviations (SD) were compiled when available or estimated using the approach of Hozo et al. [13] when medians and interquartile ranges were reported. The standard-deviation of the paired differences between baseline (T0) and last follow-up (T1) was estimated using the formula: $\sqrt{ }\left(\left(S D^{2} T 0+S D^{2} T 1\right)-(2\right.$ * $S D T 0 * S D T 1)$ ). The SMD is used as a summary statistic in meta-analysis when the studies all assess the same outcome but measure it in a variety of ways. It expresses the size of the intervention effect in each study relative to the variability observed in that study. SMD were interpreted according to Cohen rules: trivial $<0.2 \leq$ small $<0.5 \leq$ medium $<0.8 \leq$ large [14]. The aforementioned statistical approaches were used for sub-group analyses according to the stimulation techniques and target. Sub-group meta-analysis were possible when at least two studies with a similar design were available. Heterogeneity in the study results was assessed by forest plots and the $\mathrm{I}^{2}$ statistic, which is the most commonly used metric for measuring the magnitude of between-study heterogeneity and is easily interpretable. $\mathrm{I}^{2}$ values range between $0 \%$ and $100 \%$ and are typically considered low for $25 \%$, modest for $25 \%$ to $50 \%$, and high for $>50 \%$ [15]. Publication bias was assessed using funnel plots, Egger's tests, and confidence intervals.

\section{Results}

The results of the database and registry search are shown in Fig. 1. We included 38 published articles in the qualitative analysis, seven focusing on acute treatment and 31 on preventive treatment. The complete list of studies is available as online supplementary references and the characteristics of each study are summarized in Additional files 2 and 3.

\section{Acute migraine treatment}

The effect sizes for each study are presented in Fig. 2 . Sub-group meta-analysis was possible for remote electrical neuromodulation (REN; 2 studies) only.

\section{Non-invasive peripheral neurostimulation}

Two studies conducted by a single group and including one very high-quality study were positive for two-hour pain relief for remote electrical neuromodulation (REN) on the 


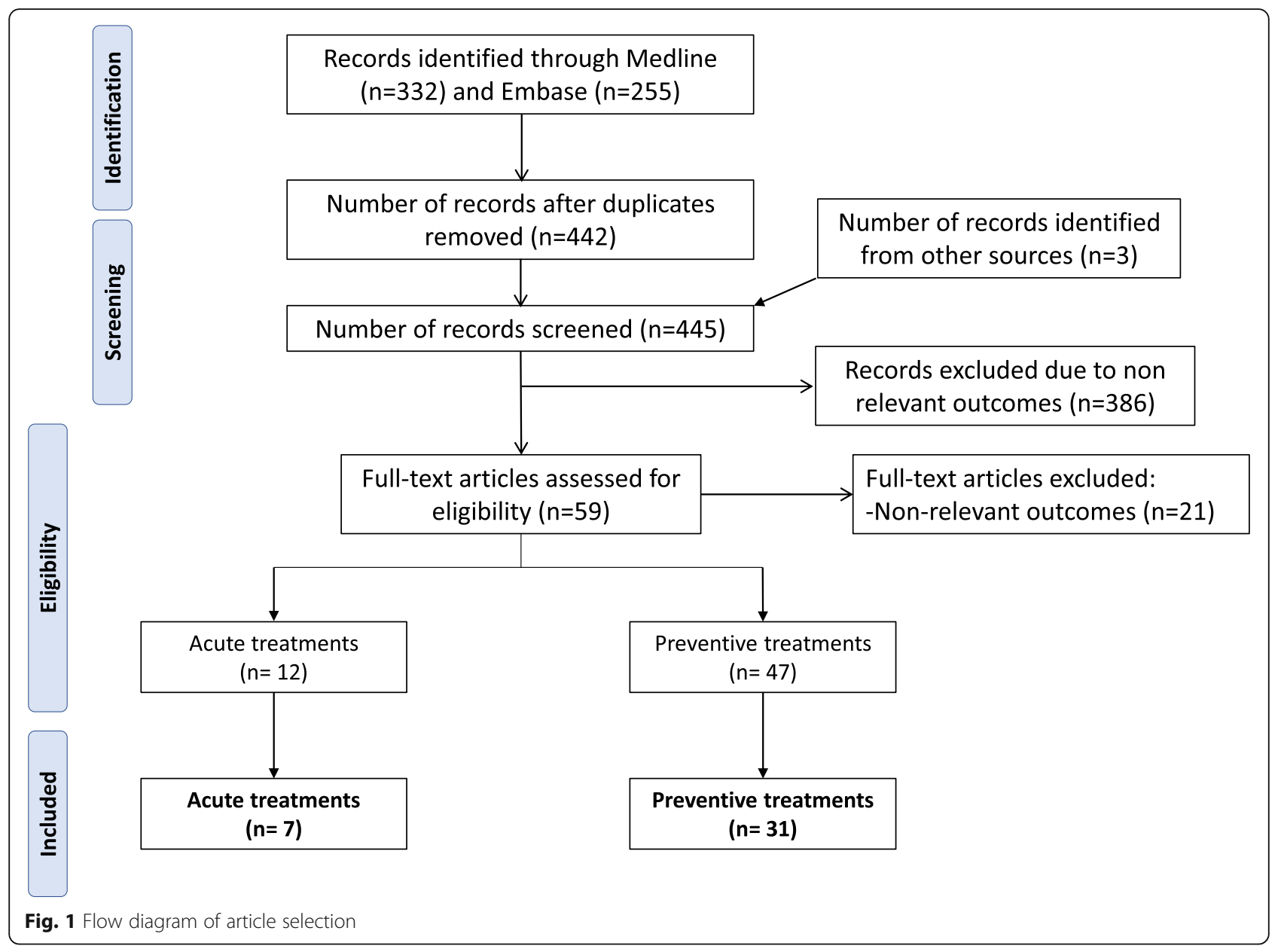

arm used as an acute treatment $[17,18]$. The NNT was 5 in the smaller study and 3.6 in the larger higher-quality study. Pooled analysis confirmed the positive effect of REN, with a large effect size $(\mathrm{RR}=2.14,95 \% \mathrm{CI}$ : $1.34-3.40)$.

Two studies of moderate [16] and very high [19] quality that tested supra-orbital transcutaneous electrical nerve stimulation (TENS) for acute treatment were positive for their primary outcomes and most secondary outcomes, although opposite results were reported for being pain free at $2 \mathrm{~h}$. It was not possible to conduct a pooled analysis of these two studies as the proportion of responders was not given in the study by Hokenek et al..

One very high-quality trial was negative for acute treatment based on the proportion of pain-free patients at $2 \mathrm{~h}$ using vagus nerve stimulation (VNS) with a Gammacore $^{\mathrm{Tw}}$ device [20].

\section{Invasive peripheral neurostimulation}

A single trial tested a minimally invasive technique. This high-quality trial evaluated the efficacy of mechanical neurostimulation at $68 \mathrm{~Hz}$ close to the sphenopalatine ganglion for $30 \mathrm{~min}$ and was positive, $50 \%$ of the patients being pain free at $2 \mathrm{~h}$ following active stimulation versus $8 \%$ with the sham [21].

\section{Non-invasive central neurostimulation}

A single very high-quality study tested single-pulse transcranial magnetic stimulation (TMS) for acute treatment of migraine with aura [22]. The study was positive for a pain-free response rate after $2 \mathrm{~h}(\mathrm{NNT}=5.9)$.

\section{Invasive central neurostimulation}

Based on our inclusion criteria, we were unable to obtain data for the use of invasive central neurostimulation techniques for migraine treatment.

\section{Preventive migraine treatment}

The effect size for each study of a preventive migraine treatment are presented in Fig. 3.

\section{Non-invasive peripheral neurostimulation}

One very high-quality study using a percutaneous mastoid electrical stimulator as preventive treatment for episodic migraine was positive with a large effect size (absolute difference of 2.87 days/month reduction) [27]. 
$\operatorname{RR}(95 \% \mathrm{Cl})$

\section{Single studies}

Chou, Supra-orbital TENS

Juto, Kinetic-oscillation stimulation

Lipton, Single-pulse TMS

Tassorelli, Vagus-nerve stimulation

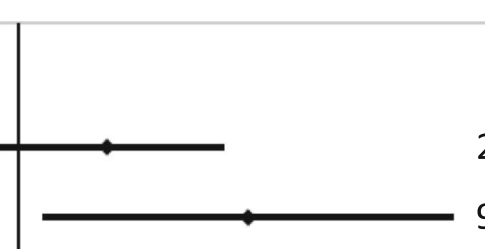

$2.34(0.77,7.12)$

$9.00(1.27,63.89)$

Tassorelli, Vagus-nerve stimulation

Remote electrical neuromodulation (REN)

Yarnitsky, 2017

Yarnitsky, 2019

Subtotal (I-squared $=0,0 \%, p=0,351)$

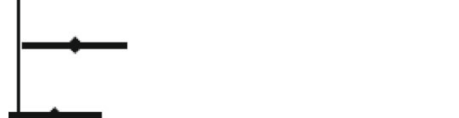

$1.72(1.09,2.82)$

$1.42(0.92,2.20)$

NOTE: Weights are from random effects analysis

\subsection{7}

1

\section{Favors sham stimulation}

\section{Favors active stimulation}

Fig. 2 Forest plot of the six studies included in the quantitative synthesis for acute migraine treatment. The common outcome for these six studies was the proportion of patients who were pain free after $2 \mathrm{~h}$ in the active treatment and control groups (the higher the relative risk, the more effective the treatment). All references for studies in this figure are listed in the online supplementary references. RR: relative risk, TENS: transcutaneous electrical nerve stimulation, TMS: transcranial magnetic stimulation. The study by Hokenek et al. of 2020 [16] (supra-orbital TENS), was not included in the quantitative analysis

One moderate-quality study using peripheral pulsed electromagnetic fields applied to the wrist was negative [28].

Five studies investigated the efficacy of TENS. Two tested supra-orbital TENS for preventive treatment. Among them, one moderate-quality study was positive and was tested as an add-on therapy [29], whereas the other high-quality-study tested TENS alone, showing a nearly significant result and becoming significant when baseline migraine days were considered as a covariate $[30,31]$. The pooled analysis confirmed the efficacy of supra-orbital TENS with a small effect size (-0.494, 95\%CI: -0.799 to -0.188$)$ and no heterogeneity $\left(\mathrm{I}^{2}=\right.$ $0 \%)$. One low-quality study tested the use of three TENS devices at the same time to stimulate the face, cervicooccipital region, and hand. TENS was used 5 days/week for three consecutive weeks and was compared to laser therapy and acupuncture [23] (qualitative analysis only). After 1 month, TENS and laser therapy where more efficient than acupuncture. Finally, two moderate-quality trials investigated the use of occipital TENS as preventive therapy. The first, using $40-\mathrm{Hz}$ stimulation, was negative [32]. Various stimulation parameters were used for the second and $100 \mathrm{~Hz}$ was positive relative to sham but less effective than topiramate. It was not possible to pool the results of these two studies, as numerical data were not available for the latter [24].

Three trials (one of moderate quality, one of high quality, and one of very high quality) tested VNS delivered using a Gammacore ${ }^{\mathrm{TM}}$ device and were negative [33-35]. The pooled analysis showed an absence of heterogeneity $\left(\mathrm{I}^{2}=0 \%\right)$ and did not demonstrate a significant positive effect of VNS $(-0.187,95 \% \mathrm{CI}$ : -0.379 to 0.004). One high-quality trial tested the use of auricular VNS (Vitos ${ }^{\mathrm{TM}}$ device) as a preventive treatment and was also negative [36].

One study tested repetitive peripheral magnetic stimulation to myofascial trigger points of the neck compared to shoulder-muscle stimulation [37]. As such peripheral magnetic stimulation has an impact on peripheral nerves, it was included in this systematic review. There was no between-group difference, although a reduction relative to baseline was noted in both groups.

\section{Invasive peripheral neurostimulation}

One high-quality study concerned percutaneous electrical nerve stimulation (PENS), which is a minimally invasive form of electrical stimulation that requires the insertion of needles for the duration of the 
a

Supra-orbital transcutaneous electrical nerve stimulation (TENS) Jiang Schoenen

Schoenen
Subtotal $\left(I^{2}=0.0 \%, p=0.480\right)$

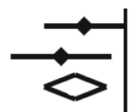

$\operatorname{SMD}(95 \% \mathrm{Cl})$

Non-invasive vagus-nerve stimulation (nVNS) Chaudry

Diener

Silberstein, 2018

Subtotal $\left(I^{2}=0.0 \%, p=0.686\right)$

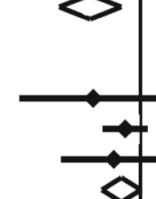

$-0.41(-0.80,-0.02)$

$-0.63(-1.12,-0.14)$

$-0.49(-0.80,-0.19)$

Percutaneous electrical nerve stimulation (PENS)

Li, 2012

Li, 2017

Subtotal $\left(1^{2}=0.0 \%, p=0.975\right)$

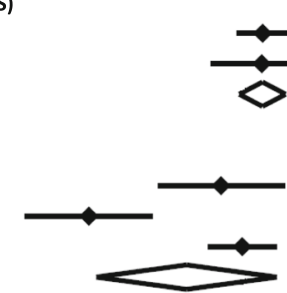

$-0.34(-0.60,-0.09)$

$-0.35(-0.85,0.15)$

$-0.34(-0.57,-0.12)$

Occipital nerve stimulation (ONS) Saper

Serra

Silberstein, 2012

Subtotal $\left(I^{2}=88.4 \%, p=0.000\right)$

$-0.75(-1.37,-0.13)$

$-2.05(-2.68,-1.42)$

$-0.54(-0.88,-0.20)$

$-1.09(-1.98,-0.20)$

Motor cortex repetitive transcranial magnetic stimulation (rTMS) Kalita

Misra

Shehata

Subtotal $\left(I^{2}=52.0 \%, p=0.124\right)$

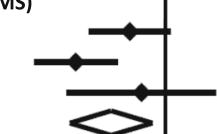

$-0.35(-0.75,0.06)$

$-0.88(-1.29,-0.47)$

$-0.23(-0.96,0.50)$

$-0.53(-0.94,-0.13)$

Prefrontal cortex repetitive transcranial magnetic stimulation (rTMS)

$$
\text { Amin }
$$

Sahu

Subtotal $\left(1^{2}=90.0 \%, p=0.002\right)$

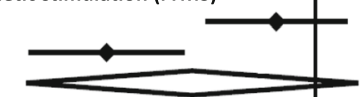

$-0.38(-1.08,0.31)$

$-2.05(-2.81,-1.29)$

$-1.21(-2.84,0.42)$

Right M1 cathodal transcranial direct current stimulation (tDCS)

Grazzi

Rahimi

Subtotal $\left(1^{2}=76.7 \%, p=0.038\right)$

NOTE: Weights are from random effects analysis

-3.76 Favors active stimulation

$-0.42(-0.84,-0.01)$

$-1.38(-2.18,-0.58)$

$-0.84(-1.76,0$.

\begin{tabular}{ccccc} 
& & \\
\hline-3.76 & Favors active stimulation & 0 & Favors sham stimulation & -3.76
\end{tabular}

b

Allais (Three TENS devices) Antal (Cathodal tDCS of the visual cortex) Auvichayapat (Left M1 anodal tDCS) Dalla Volta (Cathodal frontal tDCS) Juan (Percutaneous mastoid electrical stimulation) Liu (Occipital TENS)

Przeklasa-Muszynska (Dominant M1 anodal tDCS) Renner (Peripheral magnetic stimulation)

San-Juan (Peripheral pulsed electromagnetic fields)

Straube (Auricular nVNS)

Teepker (Vertex rTMS)

NOTE: Weights are from random effects analysis

\begin{tabular}{lllll|l}
\hline & & & \\
-3.76 & Favors active stimulation & 0 & Favors sham stimulation & -3.76
\end{tabular}

SMD $(95 \% \mathrm{Cl})$

$-0.04(-0.66,0.58)$

$-0.37(-0.92,0.18)$

$-2.83(-3.76,-1.91)$

$-0.94(-1.58,-0.31)$

$-0.81(-1.26,-0.35)$

$-0.44(-1.04,0.16)$

$0.29(-0.28,0.86)$

$-0.04(-0.68,0.61)$

$0.11(-0.55,0.76)$

$0.50(-0.08,1.09)$

$-0.06(-0.81,0.70)$

-3.76 Favors active stimulation

Favors sham stimulation

$-3.76$

Fig. 3 Forest plot of the 27 studies included in the quantitative synthesis for preventive migraine treatment (Panel $\mathbf{a}$, at least two studies. Panel $\mathbf{b}$, single studies). The common outcome was the reduction of headache days in the active treatment and control groups (the higher the reduction, the more effective the treatment). Studies using the same techniques are pooled together. All references for studies in this figure are listed in the online supplementary references. SMD: standardized mean difference, tDCS: transcranial direct current stimulation. Three studies were not included in the quantitative synthesis: Allais et al., [23] (3 TENS devices); Bono et al., [24] (occipital TENS); Jia et al., [25] (PENS); Kosari et al., [26] (tDCS over the visual cortex)

stimulation. This study performed on patients with episodic migraine was positive, with a moderate effect size (absolute difference of 1.5 days/month reduction)
[38]. Electro-acupuncture is another way to perform PENS and was tested in two studies, one very highquality study being negative on the primary outcome 
but positive on all secondary outcomes [39] and the second, of very low quality, being positive on a composite parameter that included pain intensity, pain duration, attack frequency, accompanying symptoms, and plasma 5-HT levels [25]. The last study was not usable for quantitative synthesis. The pooled analysis favored a positive effect of PENS on various acupoints, with a small effect size $(-0.344,95 \% \mathrm{CI}:-0.571$ to -0.116$)$ and the absence of heterogeneity $\left(\mathrm{I}^{2}=0 \%\right)$.

Three studies explored invasive occipital nerve stimulation (ONS), all for chronic migraine. The only highquality trial was negative for its primary outcome [40] but positive for most secondary outcomes, whereas the two others where positive for their primary outcome $[41,42]$. The pooled analysis favored a positive effect of invasive ONS, with a large effect size $(-1.090$; 95\%CI: -1.977 to $0.204)$ but high heterogeneity between studies $\left(\mathrm{I}^{2}=88 \%\right)$.

\section{Non-invasive central neurostimulation}

Six studies tested repetitive TMS (rTMS). Two (one of low quality that was negative and one of high quality that was positive) conducted by the same group used high-frequency $(10 \mathrm{~Hz}, 600$ pulses $)$ repetitive TMS over the left primary motor cortex (M1) as preventive treatment for chronic migraine [43, 44]. A single session was effective in reducing the number of headache days per month for chronic migraine sufferers, with an absolute difference of 3.2 days/month versus placebo. Three sessions did not provide greater pain reduction than a single session. One low-quality study compared botulinum toxin injection to high-frequency repetitive TMS $(10 \mathrm{~Hz}$, 2000 pulses per session) over the left M1, three times a week for four consecutive weeks, with a total follow-up of 12 weeks, on patients with chronic migraine [45]. Repetitive TMS showed no difference from botulinum toxin at weeks 4 and 8 but was less effective at week 12 . The pooled analysis of these three studies focusing on high-frequency rTMS over the left M1 favored a positive effect, with a medium effect size $(-0.533,95 \% \mathrm{CI}$ : 0.940 to -0.126$)$ and moderate heterogeneity $\left(\mathrm{I}^{2}=52 \%\right)$. Two other studies (low and moderate quality) targeting the left dorsolateral prefrontal cortex (DLPFC) were positive for their primary outcomes, using a frequency of $5 \mathrm{~Hz}$ in one case [46] and intermittent theta-burst stimulation (iTBS) in the other [47], but the first study was negative for the reduction of headache days. The pooled analysis of these two studies focusing on high-frequency rTMS over the left DLPFC did not favor a positive effect and showed high heterogeneity between studies $(-1.210$, 95\%CI: -2.844 to $\left.0.423 ; \mathrm{I}^{2}=90 \%\right)$. The last study focusing on TMS tested low-frequency repetitive TMS $(1 \mathrm{~Hz}$, 1000 pulses) over the vertex for five consecutive days compared to sham stimulation [48]. This low-quality study was negative.
Seven studies tested transcranial direct current stimulation (tDCS), with various targeted areas. Two lowquality trials tested cathodal $\mathrm{tDCS}$ over the visual cortex ( $\mathrm{Oz}$ on the International 10-20 EEG system). In one study, in which sessions were performed three times per week, for three consecutive weeks and compared to sham stimulation, was negative [49]. The second study was claimed to be positive by the authors but the poor quality of the report did not provide the opportunity to verify these results and made it impossible to integrate the results of this last study into the quantitative synthesis [26]. One moderate-quality study investigated the use of left M1 anodal tDCS for 20 consecutive days compared to sham stimulation and was positive, with an absolute difference of 1 day per month [50]. A low-quality study investigated anodal tDCS over the dominant M1 and was positive after 10 sessions applied over 30 days [51]. Another study was a moderate-quality trial comparing cathodal-tDCS over the right M1 or primary sensory cortex (S1) versus sham stimulation for 22 sessions spread over 10 consecutive weeks and was positive for the two active stimulation groups [52]. The difference was very large in both groups, with 12.47 days/month for the M1 and 9.47 for the S1 compared to sham. Another recent moderate-quality study compared anodal, cathodal, and sham tDCS over the right M1, used daily for the 5 days of treatment withdrawal for patients with chronic migraine associated with medication overuse [53]. There was no significant difference in the number of migraine days per month 12 months later. The pooled analysis of these two studies focusing on cathodal tDCS over the M1 did not favor a positive effect and showed high heterogeneity between studies $(-0.836,95 \% \mathrm{CI}$ : 1.764 to $0.091 ; \mathrm{I}^{2}=77 \%$ ). Recently, a moderate-quality study tested the use of five daily sessions of cathodal tDCS over the coolest frontal region and was positive for the number of migraine days, with a large effect size and an absolute reduction of approximately 8 days/month relative to the placebo group [54].

\section{Invasive central neurostimulation}

Our standardized search and inclusion criteria did not retrieve any studies for invasive central neurostimulation techniques for migraine treatment.

\section{Discussion}

Our systematic review and meta-analyses on noninvasive and invasive stimulation techniques for the preventive treatment of migraine favor a positive effect for invasive ONS, with a large effect size but considerable heterogeneity and a positive effect for supra-orbital TENS, PENS, and high-frequency rTMS over the M1 with small to medium effect sizes (Fig. 4). Practical information for each device is provided in Table 1. Vagus- 


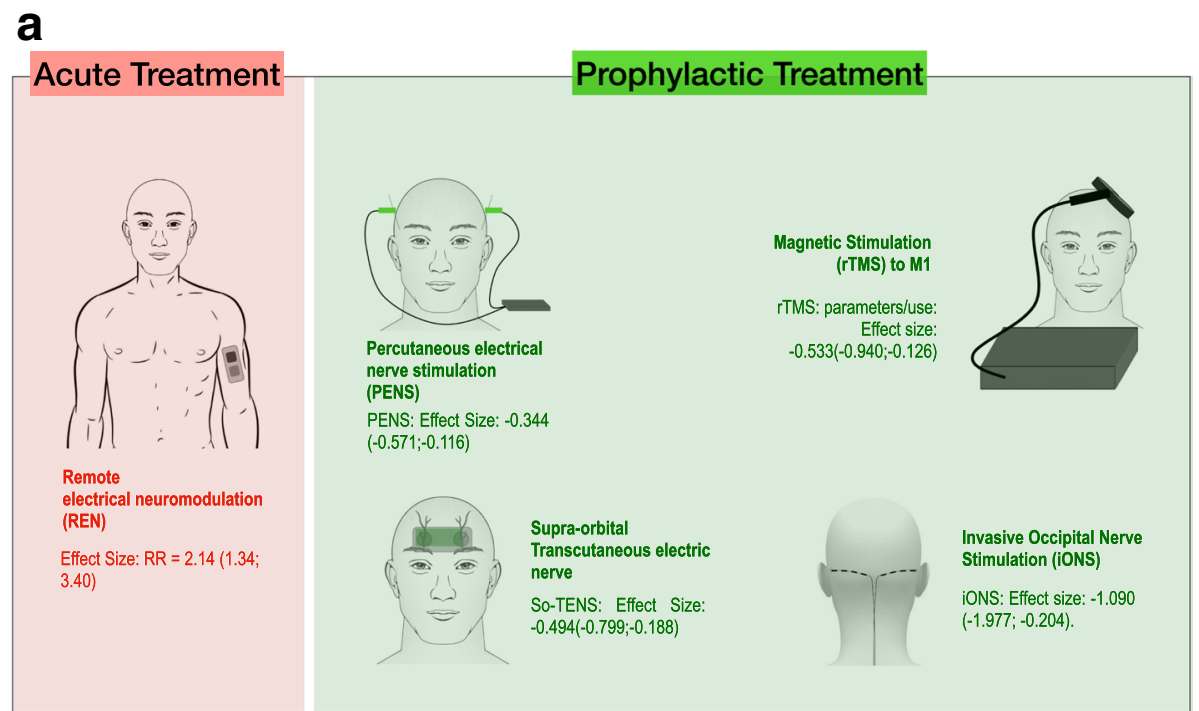

b

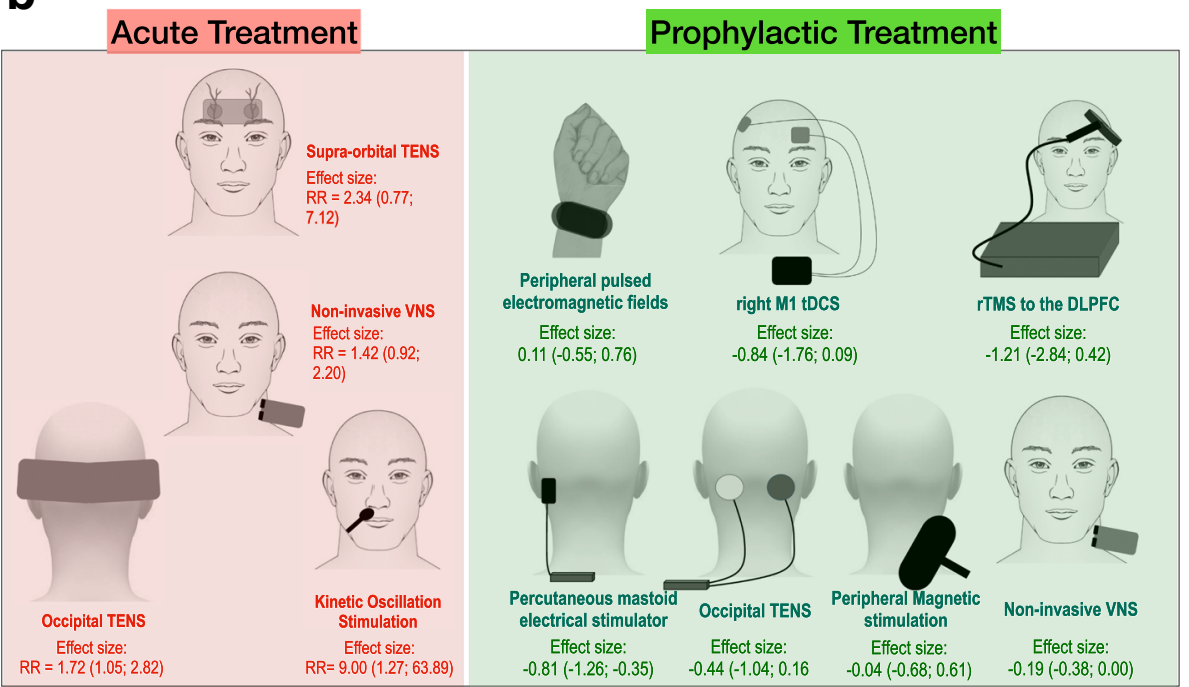

Fig. 4 Summary of neuromodulatory techniques included in the meta-analysis. a: Techniques found to be effective for acute or preventive migraine treatment according to the meta-analysis (at least 2 includable RCTs). b: Other techniques included in the meta-analysis. Effect sizes were noted as relative risk (RR) for acute treatments (the higher the RR, the more effective the method) or standardized mean difference (SMD) for preventive treatments (the more negative the SMD, the more effective the method). 95\% confidence intervals were provided (minimal; maximal). rTMS: repetitive transcranial magnetic stimulation, M1: primary motor cortex, TENS: transcutaneous electric nerve stimulation. VNS: vagus nerve stimulation, tDCS: transcranial direct current stimulation

Technical details from stimulation modalities cited in figure 4a:

REN: parameters/use: single 20-45-minute symmetrical biphasic square pulse at 80-200Hz, pulse width of 45-400 $\mu$ s, up to $40 \mathrm{~mA}$. Main side effects: local unpleasantness (common), numbness in arms and local warmth sensation (rare); [Yarnitsky 2017, Yarnitsky 2019] PENS: parameters/use: 0.18-0.32 mm x 25-40 mm needles inserted into unilateral or bilateral acupoints connected to an electro-stimulator [Taiyang EX-HN 5 for bilateral stimulation with the positive pole at the painless side of EX-HN 5 and negative pole at the painful side; for unilateral stimulation Shaoyang - "gallbladder meridian points" were used] 30-minute sessions disperse-dense waves at 2/100Hz, $5 \times$ week for 412 weeks. Main side effects: local bleeding (very common), transient leg weakness (rare) [Li H 2012, Li Y 2017]

So-TENS: parameters/use: as a stand-alone or as an add-on treatment, 30x94 mm adhesive electrode on the forehead, biphasic rectangular pulse width $30 \mu \mathrm{s}, 60 \mathrm{~Hz}$, max 16 mA, 20 min, extended for 3 months. Main side effects: paresthesia and pressure sensation over the electrode spot (common), somnolence (rare); [Jiang 2018, Schoenen 2013]. rTMS to M1: parameters/use: Figure-of-eight coil, left M1 at 10Hz, 600-3000 pulses per session, stimulation at 70-80\% below rest motor threshold, 1-10 sessions Effect size: -0.533(-0.940;-0.126). Main side effects: scalp discomfort (common), transient drowsiness (rare); [Misra 2013; Shehata 2016; Kalita 2016]. ONS: parameters/use: implanted lead (uni- or bilateral) perpendicular to the occipital nerves at the craniocervical junction. Parameter settings were bipolar montage, $50 \mathrm{~Hz}$, pulse width $330-450 \mu \mathrm{sec}$, bellow $10.5 \mathrm{~V}$ amplitude. Main side effects: lead migration, local pain over the implanted pulse generator, increase in migraine (common), local infection (rare); [Saper 2010; Silberstein 2012; Serra 2012] 
Table 1 Summary of type of stimulation, targets brand name, manufacturer, practical use and CE/FDA approval for main devices tested for migraine treatment

\begin{tabular}{|c|c|c|c|c|c|c|}
\hline Type of stimulation & Target & Brand name ${ }^{\mathrm{TM}}$ & Manufacturer & $\begin{array}{l}\text { Practical } \\
\text { use } \\
\mathrm{A}=\text { Acute } \\
\mathrm{P}= \\
\text { prophylactic }\end{array}$ & $\begin{array}{l}\text { FDA } \\
\text { cleared }\end{array}$ & $\begin{array}{l}\mathrm{CE} \\
\text { mark }\end{array}$ \\
\hline $\begin{array}{l}\text { Remote electrical nerve (REN) stimulation inducing } \\
\text { conditioned pain modulation }\end{array}$ & Arm & Nerivio Migra' ${ }^{\mathrm{M}}$ & Theranica & A & + & + \\
\hline Invasive electrical stimulation & Great occipital nerve & $\begin{array}{l}\text { Quad/Synergy } \\
\text { Genesis/Eon } \\
\text { Mini }^{\text {TMb }}\end{array}$ & $\begin{array}{l}\text { Medtronic } \\
\text { St. Jude } \\
\text { Medical-Abbott }\end{array}$ & $P$ & - & - \\
\hline Transcutaneous electrical nerve stimulation (TENS) & Supra-orbital nerve & Cefaly ${ }^{\mathrm{TM}}$ & $\begin{array}{l}\text { Cefaly } \\
\text { technology }\end{array}$ & $\mathrm{P}$ & + & + \\
\hline High frequency repetitive TMS & $\begin{array}{l}\text { Primary motor } \\
\text { cortex (M1) }\end{array}$ & More than 4 & More than 4 & $\mathrm{P}$ & + & + \\
\hline Percutaneous electric nerve stimulation (PENS) & $\begin{array}{l}\text { Shaoyang or Taiyang } \\
\text { acupoints }\end{array}$ & More than 4 & More than 4 & P & + & + \\
\hline Non-invasive vagus nerve stimulation & Cervical vagus nerve & $\begin{array}{l}\text { GammaCore }^{\text {TM }} \\
\text { NEMOS/ VITOS }\end{array}$ & $\begin{array}{l}\text { ElectroCore } \\
\text { tVNS } \\
\text { Technologies } \mathrm{GmbH}\end{array}$ & $A$ and $P$ & + & + \\
\hline Transcutaneous electrical nerve stimulation (TENS) & $\begin{array}{l}\text { Supra-orbital nerve } \\
\text { or occipital nerve }\end{array}$ & $\begin{array}{l}\text { Cefaly }^{\text {TM }} \\
\text { Headaterm }^{\mathrm{TM}} \\
\text { Relivion }^{\mathrm{TM}} \\
+ \text { Non-specific } \\
\text { TENS devices }\end{array}$ & $\begin{array}{l}\text { Cefaly technology } \\
\text { WAT medical } \\
\text { Neurolief }\end{array}$ & $A$ and $P$ & + & + \\
\hline $\begin{array}{l}\text { Single pulse transcranial magnetic stimulation } \\
\text { (TMS) }\end{array}$ & Occipital cortex & Spring TMS ${ }^{\mathrm{TM}}$ & eNeura & A & + & + \\
\hline High frequency repetitive TMS & $\begin{array}{l}\text { Dorsolateral prefrontal } \\
\text { cortex and vertex }\end{array}$ & More than 4 & More than 4 & $P$ & + & + \\
\hline Transcranial direct current stimulation (tDCS) & $\begin{array}{l}\text { M1, visual cortex, } \\
\text { frontal cortex }\end{array}$ & More than 4 & More than 4 & $P$ & + & + \\
\hline
\end{tabular}

Stimulation methods with positive effect according to pooled results of at least 2 studies included in the present review are presented above the thick line ${ }^{\mathrm{a}}$ These devices were used in the studies by Serra and Saper et al.. However, the Synergy ${ }^{\mathrm{TM}}$ generator is not manufactured any longer and replaced by the Prime Advanced $^{\mathrm{TM}}$ (non-rechargeable) or Intellis ${ }^{\mathrm{TM}}$ (rechargeable) generator

${ }^{\mathrm{b}}$ These generators are not commercialized any more by St Jude-Abbott and replaced by the Proclaim ${ }^{\mathrm{TM}}$ generators

nerve stimulation was nearly statistically significant but with an effect size below 0.2 , which is not clinically relevant. Left prefrontal cortex rTMS and tDCS over the M1 had no significant effect and the heterogeneity between studies was high in both cases. For acute treatment, REN was effective. There are very few techniques that have been evaluated appropriately in at least two randomized controlled trials, precluding any metaanalysis and conclusion in most of the other cases.

To date, the number of systematic reviews and metaanalyses focusing on neurostimulation procedure for migraine treatment is limited. There was no comprehensive review with analysis of each specific stimulation methods and targets (Table 2) [55-66]. Moreover, certain results of these previous publications are disputable, as metaanalysis pooled results from studies using different stimulation techniques (rTMS and tDCS, or TENS, VNS and PENS) or different targets (M1 and frontal or supraorbital and occipital).. Indeed, the mode of action of these various stimulation methods are different and target different cortical regions or peripheral nerves [67-69]. In the last well-conducted systematic review [70], the goal was to evaluate the scientific rigor of published studies to allow for proper comparison between devices.

Among tested devices, several are already approved for clinical use, such as the TENS device, called Cefaly ${ }^{\mathrm{ma}}$, which is CE marked and FDA cleared. Based on current evidence, it appears to be useful for preventive treatment and possibly acute treatment. The single-pulse TMS device, called SpringTMS ${ }^{\mathrm{m}}$, is also CE marked and FDA approved and appears to be useful for the acute treatment of migraine with aura. For REN, the Nerivio Migra ${ }^{\mathrm{Tm}}$ is also CE marked and FDA cleared and is useful for acute treatment. Many devices are CE marked and FDA cleared for repetitive TMS and tDCS but patient access is still limited in many countries. To date, the FDA has not cleared an invasive ONS device for the treatment of headache. The St. Jude Medical/Abbot devices (Eon, Genesis) received CE mark approval in Europe for the 
Table 2 Summary of the main results of previous systematic reviews and meta-analysis focusing on neuromodulation in migraine treatment

\begin{tabular}{|c|c|c|c|c|c|}
\hline & First author & Date & Journal & Topic & Main conclusion \\
\hline \multirow[t]{5}{*}{ rTMS / tDCS } & Fregni & 2020 & $\begin{array}{l}\text { Int J } \\
\text { Neuropsychopharmacol }\end{array}$ & $\begin{array}{l}\text { tDCS in neurological and } \\
\text { psychiatric disorders }\end{array}$ & tDCS is probably effective (Level B) for migraine \\
\hline & Baptista & 2019 & Pain reports & $\begin{array}{l}\text { Latin American and Caribbean } \\
\text { consensus on rTMS and tDCS } \\
\text { for chronic pain management }\end{array}$ & $\begin{array}{l}\text { Level B recommendation for anodal tDCS over M1 } \\
\text { or Oz/Cz tDCS. Level B recommendation for } \\
\text { high-frequency rTMS over M1 }\end{array}$ \\
\hline & Feng & 2019 & Headache & rTMS and tDCS & $\begin{array}{l}\text { Excitatory M1 stimulation showed significant effects } \\
\text { on reducing headache intensity and frequency with } \\
\text { a large effect size. Excitatory DLPFC stimulation showed } \\
\text { a significant effect on the headache intensity with a } \\
\text { large effect size but no reduction of frequency of } \\
\text { headache attacks. }\end{array}$ \\
\hline & Stilling & 2019 & Headache & $\begin{array}{l}\text { TMS and tDCS for the treatment } \\
\text { of headache }\end{array}$ & $\begin{array}{l}\text { rTMS has moderate evidence that it contributes to } \\
\text { reductions in headache frequency, duration, intensity, } \\
\text { abortive medication use, depression, and functional } \\
\text { impairment. }\end{array}$ \\
\hline & Shirahige & 2016 & Headache & rTMS and tDCS & $\begin{array}{l}\text { tDCS reduced migraine attacks frequency (SMD: }-0.75 ; 9 \\
5 \% \mathrm{Cl}:-1.25 \text { to }-0.24 ; P=.004) \text {. There was no effect } \\
\text { of rTMS. }\end{array}$ \\
\hline TMS & Lan & 2017 & J Headache Pain & $\begin{array}{l}\text { Efficacy of single-pulse TMS in } \\
\text { randomized controlled trials }\end{array}$ & $\begin{array}{l}\text { Single-pulse TMS is effective for the acute treatment of } \\
\text { migraine with aura after the first attack. The efficacy of } \\
\text { TMS on chronic migraine was not significant. }\end{array}$ \\
\hline \multirow[t]{3}{*}{ ONS } & Cadalso & 2018 & J Oral Facial Pain Headache & $\begin{array}{l}\text { ONS in intractable primary } \\
\text { headache disorders }\end{array}$ & $\begin{array}{l}3 \text { RCTs: significant reduction of headache days per } \\
\text { month (difference }=-3.061 ; 95 \% \text { confidence interval } \\
{[C \mid]=-5.162 \text { to }-0.961 ; P=.004 \text { ) compared to sham }}\end{array}$ \\
\hline & Yang & 2016 & Pain pratice & ONS for migraine & $\begin{array}{l}\text { Results from } 4 \text { retrospective studies and } 1 \text { case series } \\
\text { indicated that ONS significantly reduced the number } \\
\text { of days with headache in patients with migraine. } \\
\text { However, the evidence of ONS efficacy established } \\
\text { by } 5 \text { RCTs was limited. }\end{array}$ \\
\hline & Chen & 2015 & Plos One & ONS for chronic migraine & $\begin{array}{l}3 \text { multicenter RCTs: mean reduction of } 2.59 \text { days } \\
\text { ( } 95 \% \mathrm{Cl} 0.91 \text { to } 4.27,12=0 \% \text { ) of prolonged, moderate } \\
\text { to severe headache per month at } 3 \text { months compared } \\
\text { with a sham control. }\end{array}$ \\
\hline VNS & Lai & 2020 & Neuromodulation & $\begin{array}{l}\text { Cervical non-invasive VNS for } \\
\text { migraine and cluster headache }\end{array}$ & $\begin{array}{l}\text { No significant differences in headache days reduction } \\
(\mathrm{SMD}=-0.159 ; 95 \% \mathrm{Cl},-0.357 \text { to } 0.04 ; p=0.117) \\
\text { between } \mathrm{nVNS} \text { and sham-device treatment. }\end{array}$ \\
\hline \multirow[t]{2}{*}{ TENS } & Stanak & 2020 & J Neurol Sci & $\begin{array}{l}\text { Impact of TENS on prevention } \\
\text { and acute treatment of episodic } \\
\text { and chronic migraine }\end{array}$ & $\begin{array}{l}\text { Reduction of migraine attacks ( } 0.67 \text { less migraine attacks } \\
\text { per month), migraine days ( } 1.74 \text { less migraine days per } \\
\text { month), headache days ( } 2.28 \text { less headache days per } \\
\text { month). Concerning acute treatment, significant reduction } \\
\text { of pain at } 1 / 2 / 24 \mathrm{~h} \text { post-acute treatment. }\end{array}$ \\
\hline & Tao & 2018 & J Headache Pain & $\begin{array}{l}\text { TENS in randomized controlled } \\
\text { trials for migraine }\end{array}$ & $\begin{array}{l}\text { Significant reduction of monthly headache days } \\
\text { (SMD: }-0.48 ; 95 \% \mathrm{Cl}:-0.73 \text { to }-0.23 ; P<0.001 \text { ) }\end{array}$ \\
\hline
\end{tabular}

M1 primary motor cortex, ONS occipital nerve stimulation, $R C T$ randomized control trial, $r T M S$ repetitive transcranial magnetic stimulation, SMD standardized mean difference, $t D C S$ transcranial direct current stimulation, TENS transcutaneous electrical nerve stimulation, VNS vagus nerve stimulation

treatment of chronic migraine in 2012 but the CE mark was rescinded a few years later. Consequently, no ONS device is currently CE marked for migraine. The VNS stimulator Gammacore $^{\mathrm{Ts}}$ is also CE marked and FDA cleared but cannot be recommended for migraine treatment based on the presented data.

Several techniques are quite similar in terms of mode of action. Such is the case for occipital TENS, occipital PENS, and invasive ONS [68]. In these three instances, electrical stimulation is delivered close to the great occipital nerve and the trigemino-cervical convergence is considered to provide pain relief in the cephalic area in a referred pain pattern area. Thus, these three techniques should have comparable efficacy and one study proposed that the response to occipital TENS could be predictive of the long-term response to ONS, but very few migraine patients were included in this study [71]. There is no clear interest of PENS or occipital nerve blocks to predict ONS efficacy $[72,73]$. In the present review, the trend was the same for the three techniques and, as expected, the effect size appears to be larger for invasive techniques, especially ONS, which allows continuous and prolonged stimulation. On the contrary, non-invasive brain stimulation techniques, i.e. rTMS and tDCS, act very differently and 
provide different results in other chronic pain conditions [74]. To date, these various techniques have not been directly compared in migraine.

There are recommendations for rTMS [75], which are inconclusive for migraine. Compared to the previous work, we included one additional study in the present meta-analysis, which used botulinum toxin as a control group and did not show a significant difference. Our quantitative synthesis favors a positive effect but it is important to note that the two positive studies were conducted by a single group. Concerning the DLPFC target, two new studies have been published since the two conflicting studies discussed in the recommendations but were not eligible (less than 10 patients per study arm in both cases) for the present review [76, 77]. The longterm RCT conducted by Conforto et al. was negative [77]. Our quantitative synthesis does not favor an effect of such stimulation.

For acute treatment, REN is effective, and although one multicentred double-blind sham-controlled trial is included (very-high quality study), it must be noted that the two studies included in the quantitative synthesis were led by a single group. This technique is based on the use of conditioned pain modulation (CPM). CPM can be summarized as "pain inhibits pain". Since the use of one pain to inhibit another is not clinically appealing, these authors tested nonpainful conditioning, as it has been shown that robust nonpainful conditioning stimuli are sufficient in many cases to inhibit pain. If the results of these two studies are confirmed by an independent group, REN will definitely be an interesting option for acute migraine treatment.

\section{Limitations}

Our review had several limitations. First, our metaanalysis was based on a very limited number of articles for each study sub-group and the estimation of effect size may not be properly powered. Hence, our conclusions should be interpreted with caution. Further research is very likely to have a large impact on the confidence in the estimated effect. Even within the subgroups, in which the same technique and target were tested, the parameters could be quite different in terms of stimulation intensity and the number of sessions, again limiting the reliability of our estimates. Second, although the included studies only considered migraine patients, we cannot exclude the presence of confounding factors due to migraine frequency at baseline and potential associated medication overuse or the presence of overlapping headache disorders among the included subjects, which could affect the validity of our results. Third, the methodological quality of the included studies was heterogeneous, with only $12 / 38$ studies being of high or very high quality in the present review, as shown in previous neuromodulatory reviews for chronic pain in general [57]. Moreover, it is often difficult to obtain proper blinding in studies involving neurostimulation devices that usually induce paresthesia. Finally, the follow-up period was generally relatively short and thus long-term benefits of neuromodulation techniques are yet to be proven. Longer well-conducted studies are still needed.

\section{Conclusion}

Many neurostimulation methods have been proposed for both preventive and acute migraine treatment and there is evidence for the utility of such treatments, especially for patients that have contra-indications or intolerance to usual drugs. Although several techniques and devices appear to be effective (invasive ONS, supra-orbital TENS, PENS, and high-frequency rTMS over the M1 as prophylactic treatments; remote electrical neuromodulation for acute treatment), larger well-conducted studies are still necessary for most to confirm their efficacy and determine their true effect sizes.

\section{Supplementary Information}

The online version contains supplementary material available at https://doi. org/10.1186/s10194-020-01204-4

Additional file 1:. Search criteria and eligibility criteria.

Additional file 2.

Additional file 3.

\section{Abbreviations}

CPM: Conditioned pain modulation; DLPFC: Dorsolateral prefrontal cortex; GRADE: Grading of Recommendations Assessment, Development and Evaluation; ICHD: International classification of headache disorders; iTBS: Intermittent theta-burst stimulation; M1: Primary motor cortex; NNT: Number needed to treat; ONS: Occipital nerve stimulation; PENS: Percutaneous electrical nerve stimulation; RCT: Randomized controlled trial; REN: Remote electrical neuromodulation; RR: Relative risk;

rTMS: Repetitive transcranial magnetic stimulation; S1: Primary sensory cortex; SD: Standard-deviation; SMD: Standardized paired mean differences;

tDCS: Transcranial direct current stimulation; TENS: Transcutaneous electrical nerve stimulation; TMS: Transcranial magnetic stimulation; VNS: Vagus nerve stimulation

\section{Acknowledgements}

Not applicable.

\section{Authors' contributions}

XM and JM performed the literature search and synthesis and then wrote the first draft. XM and BP performed the statistical analysis. DCDA, DF and MLM gave a major contributor in writing the manuscript and preparing the illustrations. All authors read and approved the final manuscript.

\section{Funding}

This research received no specific grant from any funding agency in the public, commercial, or not-for-profit sectors. 


\section{Ethics approval and consent to participate}

Not applicable.

\section{Consent for publication}

Not applicable.

\section{Competing interests}

X Moisset reports fees from Lilly, TBWA, Teva, Novartis, Roche, Biogen, SanofiGenzyme, and Merck-Serono and non-financial support from SOS Oxygène, Boehringer, and Bristol Myers Squibb not related to the submitted work. B Pereira has nothing to disclose.

Daniel Ciampi de Andrade reports fees and participation in board meetings from Abbot, Medtronic, Novartis, Mundipharma, Pfizer, Grunenthal, and Merck-PG, and non-financial support from Cristalia, Magventure, Abbot, and Allergan. None of this support is related to the submitted work. D Fontaine has received personal fees and research grants from Medtronic and Saint-Jude-Abbott.

M Lanteri-Minet received grants and honoraria for advisory boards, speaker panels, or investigative studies from Allergan, Amgen, Astellas, ATI, BMS, Boehringer, Boston Scientific, CoLucid, Convergence, GlaxoSmithKline, Grunenthal, Eli Lilly, Medtronic, Menarini, MSD, Novartis, Pfizer, Reckitt Benckiser, Saint-Jude-Abbott, Sanofi-Aventis, Teva Pharmaceuticals, UCB, and Zambon. J Mawet received travel, accommodation, and meeting expenses from SOS oxygen, AMGEN, Novartis, and Homeperf and received honoraria for advisory boards from Lilly and Novartis not related to the submitted work. Boston Scientific, Medtronic, and Saint-Jude-Abbott are in the field of neuromodulation.

\section{Author details}

${ }^{1}$ Service de Neurologie, Biostatistics unit (DRCl), Université Clermont Auvergne, CHU de Clermont-Ferrand, Inserm, Neuro-Dol, 58 rue Montalembert, F-63000 Clermont-Ferrand, France. ${ }^{2}$ Department of Neurology, LIM 62 Pain Center, Universidade de São Paulo, São Paulo, Brazil. ${ }^{3}$ Department of Neurosurgery, Université Côte Azur, FHU InovPain, CHU Nice, Nice, France. ${ }^{4}$ Pain Department, Université Côte Azur, FHU InovPain, CHU Nice, Nice, France- Université Clermont-Auvergne, INSERM, Neuro-Dol, Nice, France. ${ }^{5}$ Emergency Headache Center (Centre d'Urgences Céphalées), Department of Neurology, Lariboisière Hospital, Assistance Publique des Hôpitaux de Paris, Paris, France.

Received: 30 September 2020 Accepted: 18 November 2020 Published online: 10 December 2020

\section{References}

1. GBD (2016) Neurology collaborators (2019) global, regional, and national burden of neurological disorders, 1990-2016: a systematic analysis for the global burden of disease study 2016. Lancet Neurol 18:459-480. https://doi. org/10.1016/S1474-4422(18)30499-X

2. American Headache Society (2019) The American headache society position statement on integrating new migraine treatments into clinical practice. Headache 59:1-18. https://doi.org/10.1111/head.13456

3. Galhardoni R, Correia GS, Araujo H et al (2015) Repetitive transcranial magnetic stimulation in chronic pain: a review of the literature. Arch Phys Med Rehabil 96:S156-S172. https://doi.org/10.1016/j.apmr.2014.11.010

4. Lambru G, Lanteri-Minet M (2019) Neuromodulation in headache and facial pain management: principles, Rationale and Clinical Data. Springer Nature. ISBN 10:3030141233

5. Moher D, Liberati A, Tetzlaff J et al (2009) Preferred reporting items for systematic reviews and meta-analyses: the PRISMA statement. BMJ 339:b2535

6. Headache Classification Committee of the International Headache Society (IHS) (2018) The International Classification of Headache Disorders, 3rd edition. Cephalalgia Int J Headache 38:1-211. https://doi.org/10.1177/ 0333102417738202

7. Tassorelli C, Diener H-C, Dodick DW et al (2018) Guidelines of the international headache society for controlled trials of preventive treatment of chronic migraine in adults. Cephalalgia Int J Headache 38:815-832. https://doi.org/10.1177/0333102418758283

8. Diener H-C, Tassorelli C, Dodick DW et al (2020) Guidelines for controlled trials of preventive treatment of migraine attacks in episodic migraine in adults. Cephalalgia Int J Headache 333102420941839. https://doi.org/10. $1177 / 0333102420941839$
9. Diener H-C, Tassorelli C, Dodick DW et al (2019) Guidelines of the international headache society for controlled trials of acute treatment of migraine attacks in adults: fourth edition. Cephalalgia Int J Headache 39: 687-710. https://doi.org/10.1177/0333102419828967

10. Finnerup NB, Attal N, Haroutounian S et al (2015) Pharmacotherapy for neuropathic pain in adults: a systematic review and meta-analysis. Lancet Neurol 14:162-173. https://doi.org/10.1016/S1474-4422(14)70251-0

11. Moisset X, Bouhassira D, Avez Couturier J et al (2020) Pharmacological and non-pharmacological treatments for neuropathic pain: systematic review and French recommendations. Rev Neurol (Paris) 176:325-352. https://doi. org/10.1016/j.neurol.2020.01.361

12. DerSimonian R, Laird N (2015) Meta-analysis in clinical trials revisited. Contemp Clin Trials 45:139-145. https://doi.org/10.1016/j.cct.2015.09.002

13. Hozo SP, Djulbegovic B, Hozo I (2005) Estimating the mean and variance from the median, range, and the size of a sample. BMC Med Res Methodol 5:13. https://doi.org/10.1186/1471-2288-5-13

14. Cohen J (1988) Statistical power analysis for the behavioral sciences, 2nd edn. L. Erlbaum Associates. ISBN 0-8058-0283-51

15. Higgins JPT, Thompson SG, Deeks JJ, Altman DG (2003) Measuring inconsistency in meta-analyses. BMJ 327:557-560. https://doi.org/10.1136/ bmj.327.7414.557

16. Hokenek NM, Erdogan MO, Hokenek UD et al (2020) Treatment of migraine attacks by transcutaneous electrical nerve stimulation in emergency department: a randomize controlled trial. Am J Emerg Med. https://doi.org/ 10.1016/j.ajem.2020.01.024

17. Yarnitsky D, Volokh L, Ironi A et al (2017) Nonpainful remote electrical stimulation alleviates episodic migraine pain. Neurology 88:1250-1255. https://doi.org/10.1212/WNL.0000000000003760

18. Yarnitsky D, Dodick DW, Grosberg BM et al (2019) Remote Electrical Neuromodulation (REN) Relieves Acute Migraine: A Randomized, DoubleBlind, Placebo-Controlled, Multicenter Trial. Headache. https://doi.org/10. 1111/head.13551

19. Chou DE, Shnayderman Yugrakh M, Winegarner D et al (2019) Acute migraine therapy with external trigeminal neurostimulation (ACME): a randomized controlled trial. Cephalalgia Int J Headache 39:3-14. https://doi. org/10.1177/0333102418811573

20. Tassorelli C, Grazzi L, De Tommaso M et al (2018) Non-invasive vagus nerve stimulation (nVNS) for the acute treatment of migraine: the multicenter, double-blind, randomized, sham-controlled presto trial. Headache 58:163164

21. Juto J-E, Hallin RG (2015) Kinetic oscillation stimulation as treatment of acute migraine: a randomized, controlled pilot study. Headache 55:117-127. https://doi.org/10.1111/head.12485

22. Lipton RB, Dodick DW, Silberstein SD et al (2010) Single-pulse transcranial magnetic stimulation for acute treatment of migraine with aura: a randomised, double-blind, parallel-group, sham-controlled trial. Lancet Neurol 9:373-380. https://doi.org/10.1016/S1474-4422(10)70054-5

23. Allais G, De Lorenzo C, Quirico PE et al (2003) Non-pharmacological approaches to chronic headaches: transcutaneous electrical nerve stimulation, lasertherapy and acupuncture in transformed migraine treatment. Neurol Sci Off J Ital Neurol Soc Ital Soc Clin Neurophysiol 24(Suppl 2):S138-S142. https://doi.org/10.1007/s100720300062

24. Bono F, Salvino D, Mazza MR et al (2015) The influence of ictal cutaneous allodynia on the response to occipital transcutaneous electrical stimulation in chronic migraine and chronic tension-type headache: a randomized, sham-controlled study. Cephalalgia Int J Headache 35:389-398. https://doi. org/10.1177/0333102414544909

25. Jia C, Ma X, Shi J et al (2009) Electroacupuncture at Qiuxu (GB 40) for treatment of migraine--a clinical multicentral random controlled study. J Tradit Chin Med Chung Tsa Chih Ying Wen Pan 29:43-49. https://doi.org/10. 1016/s0254-6272(09)60030-3

26. Kosari Z, Dadashi M, Zenoozian S et al (2019) Comparing the effectiveness of Neurofeedback and Transcranial direct current stimulation (tDCS) in reducing symptoms of women with migraine. J Adv Med Biomed Res 27: 23-30. https://doi.org/10.30699/jambs.27.124.23

27. Juan $Y$, Shu O, Jinhe $L$ et al (2017) Migraine prevention with percutaneous mastoid electrical stimulator: a randomized double-blind controlled trial. Cephalalgia Int J Headache 37:1248-1256. https://doi.org/10.1177/ 0333102416678623

28. San-Juan D, Pon AAL, Pohls FZ et al (2012) Peripheral pulsed electromagnetic fields may reduce the placebo effect in migraine patients 
that do not respond to the sham intervention in a randomized, placebocontrolled, double-blind, cross-over clinical trial. Complement Ther Med 20: 31-37. https://doi.org/10.1016/j.ctim.2011.09.006

29. Jiang L, Yuan DL, Li M et al (2019) Combination of flunarizine and transcutaneous supraorbital neurostimulation improves migraine prophylaxis. Acta Neurol Scand 139:276-283. https://doi.org/10.1111/ane. 13050

30. Schoenen JE (2016) Migraine prevention with a supraorbital transcutaneous stimulator: a randomized controlled trial. Neurology 86:201-202. https://doi. org/10.1212/01.wnl.0000479686.32453.cc

31. Schoenen J, Vandersmissen B, Jeangette $S$ et al (2013) Migraine prevention with a supraorbital transcutaneous stimulator: a randomized controlled trial. Neurology 80:697-704. https://doi.org/10.1212/WNL.0b013e3182825055

32. Liu Y, Dong Z, Wang R et al (2017) Migraine prevention using different frequencies of transcutaneous occipital nerve stimulation: a randomized controlled trial. J Pain Off J Am Pain Soc 18:1006-1015. https://doi.org/10. 1016/j.jpain.2017.03.012

33. Chaudhry SR, Lendvai IS, Muhammad S et al (2019) Inter-ictal assay of peripheral circulating inflammatory mediators in migraine patients under adjunctive cervical non-invasive vagus nerve stimulation (nVNS): a proof-of-concept study. Brain Stimulat 12:643-651. https://doi.org/10.1016/j.brs.2019.01.008

34. Diener H-C, Goadsby PJ, Ashina M et al (2019) Non-invasive vagus nerve stimulation (nVNS) for the preventive treatment of episodic migraine: the multicentre, double-blind, randomised, sham-controlled PREMIUM trial. Cephalalgia Int J Headache 39:1475-1487. https://doi.org/10.1177/ 0333102419876920

35. Silberstein SD, Saper JR, Mechtler LL et al (2019) The multicenter, randomised, double-blind, sham-controlled PREMIUM 2 trial: study design for evaluating non-invasive vagus nerve stimulation (nVNS) as a preventive treatment of migraines. Cephalalgia 39:275-276. https://doi.org/10.1177/ 0333102419859835

36. Straube A, Ellrich J, Eren O et al (2015) Treatment of chronic migraine with transcutaneous stimulation of the auricular branch of the vagal nerve (auricular t-VNS): a randomized, monocentric clinical trial. J Headache Pain 16:543. https://doi.org/10.1186/s10194-015-0543-3

37. Renner T, Sollmann N, Heinen F et al (2020) Alleviation of migraine symptoms by application of repetitive peripheral magnetic stimulation to myofascial trigger points of neck and shoulder muscles - a randomized trial. Sci Rep 10:5954. https://doi.org/10.1038/s41598-020-62701-9

38. Li H, Xu Q-R (2017) Effect of percutaneous electrical nerve stimulation for the treatment of migraine. Medicine (Baltimore) 96:e8108. https://doi.org/10. 1097/MD.0000000000008108

39. Li Y, Zheng H, Witt CM et al (2012) Acupuncture for migraine prophylaxis: a randomized controlled trial. CMAJ Can Med Assoc J J Assoc Medicale Can 184:401-410. https://doi.org/10.1503/cmaj.110551

40. Silberstein SD, Dodick DW, Saper J et al (2012) Safety and efficacy of peripheral nerve stimulation of the occipital nerves for the management of chronic migraine: results from a randomized, multicenter, double-blinded, controlled study. Cephalalgia Int J Headache 32:1165-1179. https://doi.org/ $10.1177 / 0333102412462642$

41. Saper JR, Dodick DW, Silberstein SD et al (2011) Occipital nerve stimulation for the treatment of intractable chronic migraine headache: ONSTIM feasibility study. Cephalalgia Int J Headache 31:271-285. https://doi.org/10. 1177/0333102410381142

42. Serra G, Marchioretto F (2012) Occipital nerve stimulation for chronic migraine: a randomized trial. Pain Physician 15:245-253

43. Kalita J, Laskar S, Bhoi SK, Misra UK (2016) Efficacy of single versus three sessions of high rate repetitive transcranial magnetic stimulation in chronic migraine and tension-type headache. J Neurol 263:2238-2246. https://doi. org/10.1007/s00415-016-8257-2

44. Misra UK, Kalita J, Bhoi SK (2013) High-rate repetitive transcranial magnetic stimulation in migraine prophylaxis: a randomized, placebo-controlled study. J Neurol. https://doi.org/10.1007/s00415-013-7072-2

45. Shehata HS, Esmail EH, Abdelalim A et al (2016) Repetitive transcranial magnetic stimulation versus botulinum toxin injection in chronic migraine prophylaxis: a pilot randomized trial. J Pain Res 9:771-777. https://doi.org/ 10.2147/JPR.S116671

46. Amin R, Emara T, Ashour $S$ et al (2020) The role of left prefrontal transcranial magnetic stimulation in episodic migraine prophylaxis. Egypt J Neurol Psychiatry Neurosurg 56. https://doi.org/10.1186/s41983019-0140-5
47. Sahu AK, Sinha VK, Goyal N (2019) Effect of adjunctive intermittent thetaburst repetitive transcranial magnetic stimulation as a prophylactic treatment in migraine patients: a double-blind sham-controlled study. Indian J Psychiatry 61:139-145. https://doi.org/10.4103/psychiatry IndianJPsychiatry_472_18

48. Teepker M, Hötzel J, Timmesfeld N et al (2010) Low-frequency rTMS of the vertex in the prophylactic treatment of migraine. Cephalalgia 30:137-144. https://doi.org/10.1111/j.1468-2982.2009.01911.x

49. Antal A, Kriener N, Lang $N$ et al (2011) Cathodal transcranial direct current stimulation of the visual cortex in the prophylactic treatment of migraine. Cephalalgia Int J Headache 31:820-828. https://doi.org/10.1177/ 0333102411399349

50. Auvichayapat P, Janyacharoen T, Rotenberg A et al (2012) Migraine prophylaxis by anodal transcranial direct current stimulation, a randomized, placebo-controlled trial. J Med Assoc Thail 95:1009-1012

51. Przeklasa-Muszyńska A, Kocot-Kępska M, Dobrogowski J et al (2017) Transcranial direct current stimulation (tDCS) and its influence on analgesics effectiveness in patients suffering from migraine headache. Pharmacol Rep PR 69:714-721. https://doi.org/10.1016/j.pharep.2017. 02.019

52. Rahimi MD, Fadardi JS, Saeidi M et al (2020) Effectiveness of cathodal tDCS of the primary motor or sensory cortex in migraine: a randomized controlled trial. Brain Stimulat 13:675-682. https://doi.org/10.1016/j.brs.2020. 02.012

53. Grazzi L, Usai S, Bolognini N et al (2020) No efficacy of transcranial direct current stimulation on chronic migraine with medication overuse: A double blind, randomised clinical trial. Cephalalgia 0333102420931050. https://doi. org/10.1177/0333102420931050

54. Dalla Volta G, Marceglia S, Zavarise P, Antonaci F (2020) Cathodal tDCS guided by thermography as adjunctive therapy in chronic migraine patients: a sham-controlled pilot study. Front Neurol 11:121. https://doi.org/ 10.3389/fneur.2020.00121

55. Tao H, Wang T, Dong $X$ et al (2018) Effectiveness of transcutaneous electrical nerve stimulation for the treatment of migraine: a meta-analysis of randomized controlled trials. J Headache Pain 19(1):42. https://pubmed.ncbi. nlm.nih.gov/29845369/. Accessed 1 July 2020

56. Feng Y, Zhang B, Zhang J, Yin Y (2019) Effects of non-invasive brain stimulation on headache intensity and frequency of headache attacks in patients with migraine: a systematic review and meta-analysis. Headache 59 1436-1447. https://doi.org/10.1111/head.13645

57. Baptista AF, Fernandes AMBL, Sá KN et al (2019) Latin American and Caribbean consensus on noninvasive central nervous system neuromodulation for chronic pain management (LAC2-NIN-CP). Pain Rep 4: e692. https://doi.org/10.1097/PR9.0000000000000692

58. Chen Y-F, Bramley G, Unwin G et al (2015) Occipital nerve stimulation for chronic migraine--a systematic review and meta-analysis. PLoS One 10: e0116786. https://doi.org/10.1371/journal.pone.0116786

59. Shirahige L, Melo L, Nogueira F et al (2016) Efficacy of noninvasive brain stimulation on pain control in migraine patients: a systematic review and meta-analysis. Headache 56:1565-1596. https://doi.org/10. 1111/head.12981

60. Yang Y, Song M, Fan Y, Ma K (2016) Occipital nerve stimulation for migraine: a systematic review. Pain Pract Off J World Inst Pain 16:509-517. https://doi.org/10.1111/papr.12303

61. Lan L, Zhang $X$, Li $X$ et al (2017) The efficacy of transcranial magnetic stimulation on migraine: a meta-analysis of randomized controlled trails. J Headache Pain 18:86. https://doi.org/10.1186/s10194-017-0792-4

62. Cadalso RT, Daugherty J, Holmes C et al (2018) Efficacy of electrical stimulation of the occipital nerve in intractable primary headache disorders: a systematic review with meta-analyses. J Oral Facial Pain Headache 32:4052. https://doi.org/10.11607/ofph.1784

63. Stilling JM, Monchi O, Amoozegar F, Debert CT (2019) Transcranial magnetic and direct current stimulation (TMS/tDCS) for the treatment of headache: a systematic review. Headache 59:339-357. https://doi.org/10.1111/head. 13479

64. Fregni F, El-Hagrassy MM, Pacheco-Barrios K et al (2020) Evidence-based guidelines and secondary meta-analysis for the use of transcranial direct current stimulation (tDCS) in neurological and psychiatric disorders. Int J Neuropsychopharmacol. https://doi.org/10.1093/ijnp/pyaa051

65. Lai Y-H, Huang Y-C, Huang L-T et al (2020) Cervical noninvasive Vagus nerve stimulation for migraine and cluster headache: a systematic review and 
meta-analysis. Neuromodulation J Int Neuromodulation Soc 23:721-731. https://doi.org/10.1111/ner.13122

66. Stanak M, Wolf S, Jagoš H, Zebenholzer K (2020) The impact of external trigeminal nerve stimulator (e-TNS) on prevention and acute treatment of episodic and chronic migraine: a systematic review. J Neurol Sci 412:116725. https://doi.org/10.1016/j.jns.2020.116725

67. Moisset X, de Andrade DC, Bouhassira D (2016) From pulses to pain relief: an update on the mechanisms of rTMS-induced analgesic effects. Eur J Pain Lond Engl 20:689-700. https://doi.org/10.1002/ejp.811

68. Moisset X, Lanteri-Minet M, Fontaine D (2019) Neurostimulation methods in the treatment of chronic pain. J Neural Transm Vienna Austria 1996. https:// doi.org/10.1007/s00702-019-02092-y

69. Moisset X, Lefaucheur J-P (2019) Non pharmacological treatment for neuropathic pain: invasive and non-invasive cortical stimulation. Rev Neurol (Paris) 175:51-58. https://doi.org/10.1016/..neurol.2018.09.014

70. Reuter U, McClure C, Liebler E, Pozo-Rosich P (2019) Non-invasive neuromodulation for migraine and cluster headache: a systematic review of clinical trials. J Neurol Neurosurg Psychiatry. https://doi.org/10.1136/jnnp2018-320113

71. Nguyen J-P, Nizard J, Kuhn E et al (2016) A good preoperative response to transcutaneous electrical nerve stimulation predicts a better therapeutic effect of implanted occipital nerve stimulation in pharmacologically intractable headaches. Neurophysiol Clin Clin Neurophysiol 46:69-75. https://doi.org/10.1016/..neucli.2015.12.002

72. Kinfe TM, Schuss P, Vatter H (2015) Occipital nerve block prior to occipital nerve stimulation for refractory chronic migraine and chronic cluster headache: myth or prediction? Cephalalgia Int J Headache 35:359-362. https://doi.org/10.1177/0333102414541685

73. Kinfe TM, Pintea B, Roeske S et al (2016) Percutaneous nerve field stimulation (PENS) of the occipital region as a possible predictor for occipital nerve stimulation (ONS) responsiveness in refractory headache disorders? A feasibility study. Cephalalgia Int J Headache 36:779-789. https://doi.org/10.1177/0333102415613765

74. Attal N, Ayache SS, Ciampi De Andrade D et al (2016) Repetitive transcranial magnetic stimulation and transcranial direct-current stimulation in neuropathic pain due to radiculopathy: a randomized sham-controlled comparative study. Pain 157:1224-1231. https://doi.org/10.1097/j.pain. 0000000000000510

75. Lefaucheur J-P, Aleman A, Baeken C et al (2020) Evidence-based guidelines on the therapeutic use of repetitive transcranial magnetic stimulation (rTMS): an update (2014-2018). Clin Neurophysiol Off J Int Fed Clin Neurophysiol 131:474-528. https://doi.org/10.1016/j.clinph.2019.11.002

76. Brighina F, Piazza A, Vitello G et al (2004) rTMS of the prefrontal cortex in the treatment of chronic migraine: a pilot study. J Neurol Sci 227:67-71. https://doi.org/10.1016/j.jns.2004.08.008

77. Conforto AB, Amaro E, Gonçalves AL et al (2014) Randomized, proof-ofprinciple clinical trial of active transcranial magnetic stimulation in chronic migraine. Cephalalgia 34:464-472. https://doi.org/10.1177/ 0333102413515340

\section{Publisher's Note}

Springer Nature remains neutral with regard to jurisdictional claims in published maps and institutional affiliations.

Ready to submit your research? Choose BMC and benefit from:

- fast, convenient online submission

- thorough peer review by experienced researchers in your field

- rapid publication on acceptance

- support for research data, including large and complex data types

- gold Open Access which fosters wider collaboration and increased citations

- maximum visibility for your research: over $100 \mathrm{M}$ website views per year

At BMC, research is always in progress.

Learn more biomedcentral.com/submissions 